\title{
PERBANDINGAN METODE ANN-PSO DAN ANN-GA UNTUK PENINGKATAN AKURASI PREDIKSI HARGA EMAS ANTAM
}

\author{
Nadia Annisa Maori \\ Fakultas Sains dan Teknologi UNISNU Jepara \\ nadia@unisnu.ac.id
}

\begin{abstract}
Antam's gold price is more expensive than the price of gold used by more investors for long-term use. Sometimes the price of antam gold cannot be predicted at any time. Antam's rising gold prices were moved by many factors, sent in exchange rates of US dollars (USD). If the exchange rate of the US dollar (USD) decreases, the price of gold will rise and vice versa, if the value of the US dollar (USD) strengthens, the price of gold will increase. This condition makes it difficult for investors to predict the price of gold in the future. Backpropagation Artificial Neural Network (ANN) is known as one of the good methods in predicting. In this study an evaluation of the results of the price of gold using ANN with the help of PSO (Particle Swarm Optimization) and GA (Genetic Algorithm) optimization. PSO has many similarities with $G A$, which is an algorithm adopted from the process of supporting humans. The results of the study prove that PSO Optimization is able to provide an increase in optimizing the weights on the Neural Network by producing the best RMSE value, which is equal to 0.026, while GA optimization only produces a value of 0.09 .
\end{abstract}

Keywords : antam, gold, artificial, neural, network

\begin{abstract}
Abstrak
Harga emas antam yang cenderung lebih mahal dibandingkan harga emas biasa dijadikan banyak investor untuk berinvestasi jangka panjang.Terkadang harga emas antam tidak dapat diprediksi setiap saat.Naik turun harga emas antam dipengaruhi oleh banyak faktor, diantaranya adalah nilai tukar dolar Amerika (USD). Apabila nilai penukaran dolar Amerika (USD) melemah, maka harga emas cenderung naik dan juga berlaku sebaliknya,jika nilai penukaran dolar Amerika (USD) menguat, maka harga emas akan cenderung turun.Kondisi ini yang menyebabkan investor mengalami kesulitan untuk memprediksi harga emas antam di masa mendatang. Artificial Neural Network (ANN) Backpropagation dikenal sebagai salah satu metode yang baik dalam memprediksi.Pada penelitian ini dilakukan perbandingan hasil prediksi harga emas antam menggunakan ANN dengan bantuan optimasi PSO (Particle Swarm Optimization) dan GA (Genetic Algorithm). PSO memiliki banyak persamaan dengan GA, yaitu sebuah algoritma yang diadopsi dari proses evolusi manusia. Hasil penelitian ini membuktikan bahwa Optimasi PSO mampu memberikan pengaruh dalam mengoptimasi bobot pada Neural Network dengan menghasilkan nilai RMSE yang paling baik, yaitu sebesar 0.026, sementara optimasi GA hanya menghasilkan nilai RMSE sebesar 0.029 .
\end{abstract}

Kata kunci : emas, antam, artificial, neural, network

\section{PENDAHULUAN Latar Belakang}

Pertumbuhan ekonomi suatu Negara sangat mempengaruhi peningkatan investasi di negara tersebut. Investasi merupakan salah satu bentuk nyata dari motif seseorang, investor, maupun organisasi saat memegang dana tunai (Kusumadewi dan Purnomo, 2005). Mulai dari masyarakat menengah kebawah sampai keatas, investasi mulai dilirik karena investasi dapat menjadi pemasukan tambahan bagi para investor.Selain saham, emas merupakan investasi yang cukup menjanjikan dan banyak diminati oleh investor.

Emas merupakan asset yang memiliki nilai tinggi dan akan naik setiap saat. Harga emas antam yang cenderung lebih mahal dibandingkan harga emas biasa dijadikan banyak investor untuk berinvestasi jangka panjang.Terkadang harga emas antam tidak dapat diprediksi setiap saat. Naik turun harga emas antam dipengaruhi oleh banyak faktor, 
diantaranya adalah krisis financial, naiknya permintaan emas dipasaran, kurs dollar, harga minyak dan situasi politik dunia..

Dengan minat para investor yang cukup tinggi tersebut, maka suatu estimasi atau ramalan harga dimasa mendatang perlu di observasi dengan alat prediksi yang efektif. Peramalan harga emas merupakan salah satu cara untuk memprediksi atau memperkirakan harga emas dimasa yang akan dating berdasarkan data di masa lalu yang dapat digunakan sebagai alat untuk berinvestasi. Peramalan dibutuhkan karena dunia bisnis berhadapan dengan ketidakpastian dimasa depan dengan menentukan model alat prediksi yang efektif yang akhirnya dapat meningkatkan jumlah investor dan par investor tidak ragu dalam melakukan investasi emas (Alkaf, dkk, 2017).

Backpropagation merupakan metode dalam Artificial Neural Network yang memiliki tingkat akurasi yang tinggi dalam penerapan pada prediksi [8]. Pada penelitian ini akan dilakukan perbandingan hasil prediksi harga emas antam menggunakan ANN dengan bantuan optimasi PSO (Particle Swarm Optimization) dan GA (Genetic Algorithm). Data yang digunakan berupa data sekunder yang diperoleh dari website resmi harga emas. Data ini berupa time series, yaitu periode dari tahun 2016 sampai dengan 2018 dan merupakan data univariat, yaitu hanya memiliki 1 atribut saja (harga emas). Data yang digunakan harga emas antam $1 \mathrm{gram}$.

PSO memiliki banyak kesamaan dengan teknik komputasi evolusioner seperti Genetic Algorithm (GA). Sistem ini diinisialisasi dengan populasi solusi acak dan pencarian nilai optimal dengan memperbarui generasi. Namun, tidak seperti GA, PSO tidak memiliki operator evolusi seperti crossover dan mutasi.Di PSO, solusi potensial yang disebut partikel akan terbang melalui ruang masalah dengan mengikuti partikel optimum setiap iterasi.

Dibandingkan dengan GA, kelebihan PSO adalah mudah diimplementasikan dan hanya ada beberapa parameter yang bias disesuaikan. PSO telah berhasil diterapkan di banyak bidang: optimasi fungsi, pelatihan jaringan syaraf tiruan, kontrol sistem fuzzy, dan area lain dimana GA dapat diterapkan.
Penerapan model ANN dan GA mampu memberikan hasil yang cukup akurat yang diperlihatkan dari kedekatan antara target dengan output (www.harga-emas.org). Hasil penelitian ini untuk mengetahui optimasi mana yang lebih baik untuk menghasilkan prediksi harga emas antam.

\section{Rumusan Masalah}

Berdasarkan latar belakang diatas, dapat dirumuskan permasalahan yang akan diselesaikan adalah untuk melakukan prediksi harga emas antam menggunakan ANN-PSO dan ANN-GA.

\section{Batasan Masalah}

Batasan masalah yang digunakan dalam penelitian ini, yaitu data yang digunakan adalah data kuantitatif, yaitu harga emas. Data ini merupakan data time series yang diperoleh dari website resmi Harga Emas harian dari tanggal 1 Januari tahun 2016 sampai dengan 30 September 2018 dan dalam melakukan eksperimen menggunakan bantuan tools RapidMiner 5 untuk mendapatkan RMSE yang paling minimal.

\section{Tujuan Penelitian}

Tujuan penelitian ini adalah untuk melakukan prediksi harga emas antam menggunakan ANN-PSO dan ANN-GA untuk mengetahui performa Neural Network dalam melakukan prediksi, serta untuk mengetahui perbandingan optimasi PSO dan GA dalam menghasilkan nilai error yang minimal.

\section{METODE PENELITIAN}

Metode yang digunakan dalam penelitian adalah menggunakanNeural Network dengan bantuan optimasi bobot dari Particle Swarm Optimization (PSO) dan Genetic Algorithm (GA). Pembentukan model prediksi dimaksudkan untuk menentukan parameter dari arsitektur jaringan yang akan digunakan untuk pembelajaran.

Eksperimen dan pengujian pada penelitian ini menggunakan alat bantu software Rapidminer untuk mengimplementasikan algoritma ANN-PSO dan ANN-GA dengan menentukan jumlah data training dan data testing dengan presentase $90 \%$ untuk data training dan $10 \%$ untuk data testing. Langkahlangkah eksperimen dan pengujian dalam menentukan model prediksi pada penelitian ini antara lain : 


\section{Pengolahan Data Awal}

Data yang sudah diperoleh akan dilakukan preprocessing data, yaitu normalisasi data dalam jangkauan $[0,1]$ terlebih dahulu menggunakan Microsoft Excel. Dari hasil normalisasi tersebut kemudian diubah menjadi bentuk data pelatihan untuk menentukan jumlah inputan terbaik. Untuk penelitian ini dilakukan uji coba dengan mengubah data pelatihan menjadi 2 inputan sampai dengan 10 inputan.

\section{Penentuan Parameter Neural Network}

a. Training cycle

Training cycle atau biasa disebut juga dengan iterasi (epoch) adalah banyaknya pengulangan pada tahapan pelatihan algoritma.Penentuan training cycle untuk uji coba dalam penelitian ini memasukkan nilai dengan range 100 sampai dengan 2000, serta nilai 0.3 untuk learning rate dan 0.2 untuk momentum.

b. Learning rate

Learning rate salah satu parameter dari neural network yang digunakan oleh algoritma untuk melakukan bobot dari neuron. Nilai learning rate mulai dari 0 sampai dengan 1 , semakin besar nilai yang diberikan menyebabkan pembelajaran lebih cepat, tetapi ada osilasi bobot, sedangkan jika nilai learning rate semakin kecil proses pembelajaran lebih lambat. Untuk mendapatkan nilai learning rate dilakukan uji coba memasukkan nilai pelatihan $[0,1 \ldots 1]$, serta memasukkan training cycle dengan hasil RMSE terkecil dari percobaan sebelumnya dan nilai momentum 0.2 .

\section{c. Momentum}

Batasan nilai momentum adalah mulai dari 0 sampai dengan 1. Momentum berfungsi untuk meningkatkan convergance, mempercepat waktu proses pembelajaran dan mengurangi osilasi. Untuk mendapatkan nilai momentum dilakukan uji coba memasukkan nilai pelatihan $[0,1 . .0,9]$, untuk parameter training cycle dan learning rate nilainya diambil dari hasil percobaan sebelumnya dengan RMSE terkecil.

\section{d. Input Layer}

Input layer merupakan nilai jumlah data yang dimasukkan yang digunakan sebagai pembelajaran. Penentuan input layer biasanya tidak lebih dari variabel atau jumlah data yang ada.

e. Hidden Layer

Jumlah hidden layer boleh memiliki lebih dari satu hidden layer atau bahkan bisa juga tidak memilikinya sama sekali. Namun jika jumlah neuron terlalu sedikit akan mengakibatkan underfitting, yaitu jaringan kurang dapat mendeteksi sinyal atau pola dalam set data dan sebaliknya jika jumlah neuron terlalu banyak akan mengakibatkan overfitting, yaitu jumlah informasi dalam training set jadi terbatas, tidak cukup untuk melatih semua neuron dalam hidden layer. Untuk penelitian ini, penentuan hidden layer adalah 1 dengan menguji neuron size 1 sampai dengan 30 .

f. Output Layer

Output layer merupakan jumlah berapa banyak keluaran dari hasil proses pembelajaran algoritma neural network. Dalam penelitian ini penentuan output layer adalah 1 output layer.

\section{Penentuan Parameter Particle Swarm Optimization}

Pada tahap ini struktur Neural Network yang dihasilkan dari percobaan sebelumnya dioptimasi dengan Particle Swarm Optimization (PSO). Parameter weight pbest, weight gbest dan population size yang digunakan dalam penelitian ini mengacu pada penelitian Joko S. Dwi Raharjo (2013), dimana nilai weight pbest dan weight gbest adalah 2.0, sedangkan parameter pembobotan (inertia weight, max weight dan $\min$ weight) menggunakan system default yang ada pada rapidminer, dimana nilai insertia weight adalah 1.0, nilai max weight adalah 1.0, dan nilai minweight adalah 0.0 dan untuk penentuan nilai population size dilakukan pengujian dengan memasukkan nilai range 5 sampai dengan 20.

\section{Penentuan Parameter Genetic Algorithm}

Pada tahap ini struktur Neural Network yang dihasilkan dari percobaan sebelumnya dioptimasi dengan Genetic Algorithm dengan system default yang ada di rapidminer, dimana nilai population size adalah 10 , generation max adalah 100, serta nilai untuk crossover adalah 0.9. Kemudian dilakukan penambahan 
population size untuk mencari model yang ideal atau yang terbaik.

Penentuan parameter yang sudah dibahas sebelumnya bertujuan untuk menentukan model terbaik dari metode yang dipilih untuk melakukan prediksi harga emas antam.

\section{HASIL PENELITIAN DAN PEMBAHASAN}

Proses awal sebelum dilakukan pengujian terhadap metode yang sudah diusulkan, yaitu ANN-PSO dan ANN-GA adalah tahap preprocessing. Tahap preprocessing yang digunakan pada penelitian ini adalah normalisasi data. Data yang sudah diperoleh, kemudian dilakukan normalisasi data kemudian diubah menjadi bentuk data pelatihan untuk menentukan jumlah inputan terbaik. Untuk penelitian ini dilakukan uji coba dengan mengubah data pelatihan menjadi 2 inputan sampai dengan 10 inputan. Dari uji coba tersebut, dihasilkan data pelatihan yang terbaik adalah dengan menggunakan 5 inputan. Untuk selanjutnya, data pelatihan tersebut dapat digunakan untuk melakukan pengujian penentuan parameter Neural Network, Particle Swarm Optimization, dan Genetic Algorithm.

\section{Metode Neural Network}

Pada penelitian ini, pengujian dilakukan menggunakan Neural Network dimaksudkan untuk mendapatkan parameter terbaik yang menghasilkan nilai RMSE terkecil. Dari hasil pengujian yang sudah dilakukan didapatkan parameter terbaik untuk Neural Network dengan nilai RMSE sebesar 0.030 yang dapat dilihat pada Tabel 1 di bawah ini.

Tabel 1. Penentuan Parameter Neural Network

\begin{tabular}{|l|c|}
\hline \multicolumn{1}{|c|}{ Parameter } & Nilai \\
\hline Input Layer & 5 \\
\hline Training Cycle & 500 \\
\hline Learning Rate & 0.1 \\
\hline Momentum & 0.1 \\
\hline Hidden Layer & 2 \\
\hline RMSE & 0.030 \\
\hline
\end{tabular}

Dari parameter diatas, selanjutnya akan dilakukan optimasi bobot menggunakan PSO dan GA untuk mengoptimasi bobot pada
Neural Network sehingga akan menghasilkan nilai RMSE yang lebih optimal.

Dari parameter diatas, maka didapat arsitektur Neural Network. Gambar arsitektur Neural Network dapat ditunjukkan pada Gambar 1 di bawah ini.

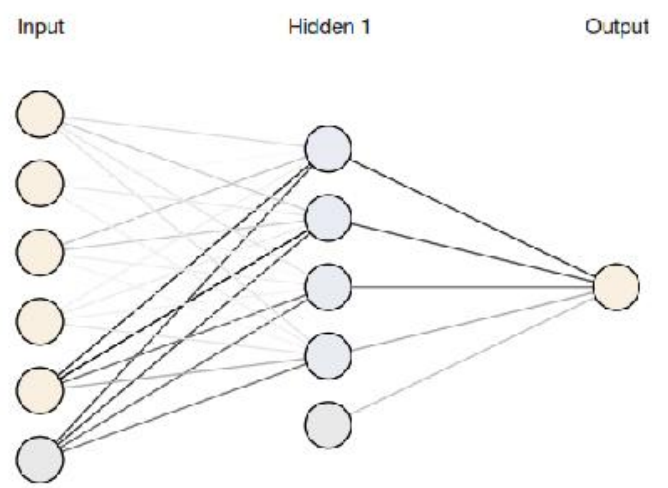

Gambar 1. Arsitektur Neural Network

\section{Metode Neural Network berbasis Particle Swarm Optimization}

Setelah mendapat parameter terbaik dari Neural Network, selanjutnya pengujian dilakukan dengan mengoptimasi bobot pada Neural Network menggunakan Particle Swarm Optimization untuk mendapatkan parameter terbaik dari PSO. Dari hasil pengujian yang sudah dilakukan didapatkan parameter terbaik untuk ANN-PSO dengan nilai RMSE sebesar 0.026 yang dapat dilihat pada Tabel 2 di bawah ini.

Tabel 2. Penentuan Parameter Neural Network dan Particle Swarm Optimization

\begin{tabular}{|l|c|}
\hline \multicolumn{1}{|c|}{ Parameter } & Nilai \\
\hline Input Layer & 5 \\
\hline Training Cycle & 500 \\
\hline Learning Rate & 0.1 \\
\hline Momentum & 0.1 \\
\hline Hidden Layer & 2 \\
\hline Insertia Weight & 1.0 \\
\hline Max Weight & 1.0 \\
\hline MinWeight & 0.0 \\
\hline Population Size & 5 \\
\hline RMSE & 0.026 \\
\hline
\end{tabular}

Dari hasil pengujian di atas, selanjutnya akan dibandingkan dengan pengujian Neural Network dan GA. 


\section{Metode Neural Network Berbasis Genetic Algorithm}

Selanjutnya dilakukan pengujian Neural Network dan GA, dengan menggunakan parameter terbaik dari Neural Network yang sudah didapatkan pada pengujian awal. Pengujian dilakukan untuk menentukan parameter terbaik dari GA, sehingga akan menghasilkan nilai RMSE yang optimal. Dari hasil pengujian yang sudah dilakukan didapatkan ANN-GA dengan nilai RMSE sebesar 0.029 yang dapat dilihat pada Tabel 3 di bawah ini.

Tabel 3. Penentuan Parameter Neural Network dan Genetic Algorithm

\begin{tabular}{|l|c|}
\hline \multicolumn{1}{|c|}{ Parameter } & Nilai \\
\hline Input Layer & 5 \\
\hline Training Cycle & 500 \\
\hline Learning Rate & 0.1 \\
\hline Momentum & 0.1 \\
\hline Hidden Layer & 2 \\
\hline generation max & 100 \\
\hline crossover & 0.9 \\
\hline Population Size & 10 \\
\hline RMSE & 0.029 \\
\hline
\end{tabular}

\section{Analisa Perbandingan ANN-PSO dan ANN- GA}

Dari percobaan yang sudah dilakukan, yaitu pengujian untuk menentukan parameter neural network, neural network dan PSO, serta neural network dan GA selanjutnya dilakukan analisa perbandingan performa dalam mengoptimasi bobot pada neural network. Hasil percobaan dari ketiga percobaan dapat ditunjukkan pada Tabel 4 di bawah ini.

Tabel 4. Perbandingan Hasil RMSE

\begin{tabular}{|l|c|}
\hline \multicolumn{1}{|c|}{ Metode } & RMSE \\
\hline Neural Network & 0.030 \\
\hline $\begin{array}{l}\text { Neural Network dan Particle } \\
\text { SwarmOptimization }\end{array}$ & 0.026 \\
\hline $\begin{array}{l}\text { Neural Network dan Genetic } \\
\text { Algorithn }\end{array}$ & 0.029 \\
\hline
\end{tabular}

Dari hasil yang diperoleh, dapat disimpulkan bahwa Neural Network dan PSO menghasilkan nilai RMSE yang terbaik, yaitu sebesar 0.026. Ini membuktikan bahwa PSO mampu memberikan pengaruh dalam mengoptimalkan bobot pada neural network dalam melakukan prediksi.

\section{SIMPULAN}

Berdasarkan percobaan dalam penelitian yang sudah dilakukan, dapat ditarik kesimpulan bahwa :

1. Penentuan parameter dari penelitian ini dapat diperoleh model terbaik pada neural network dengan parameter nilai untuk training cycle adalah 500, learning rate dan momentum sebesar 0.1 , serta neuron size adalah 2, pada particle swarm optimization nilai insertia weight adalah 1.0, global best weight dan local best weight sebesar 0.2 , serta population size adalah 5, dan pada genetic algorithm nilai generation max adalah 100, crossover adalah 5,dan population size adalah 10.

2. Pengujian model neural network yang dioptimasi dengan menggunakan particle swarm optimization menghasilkan nilai rmse sebesar 0.026 dan GA sebesar 0.029 sementara hasil RMSE pengujian menggunakan neural network saja sebesar 0.030

3. Dari hasil RMSE yang diperoleh pada kesimpulan nomor 2 membuktikan bahwa metode optimasi Particle Swarm Optimization dalam optimasi bobot terbukti dapat menghasilkan nilai akurasi yang lebih baik dibandingkan dengan optimasi genetic algorithm.

4. Penyesuaian jumlah populasi dapat memberikan optimasi yang lebih baik, tetapi diikuti dengan penambahan waktu komputasi.

\section{Saran}

Saran yang dapat digunakan untuk penelitian berikutnya untuk mencapai hasil yang lebih baik adalah diharapkan pada penelitian berikutnya dapat dikembangkan dengan menggunakan metode optimasi lainnya, seperti Artificial Bee Colony, dan lainlain.

\section{DAFTAR PUSTAKA}

Alkaf, Fatima Tuzzahara, Dharma Putra, Subagyo. (2017). Analisis Penjualan Emas dan Penerapan Model estimasi Yang Efektif Pada PT Aneka Tambang. 
Journal of Applied Business and Economics, Vol. 4, 236-249.

Jain, T. R., \& P., K. O. (2007). Economic Concept and Methods. New Delhi: VK. Publication.

Kusumadewi S., Purnomo H. 2005. Penyelesaian Masalah Optimasi dengan Teknik-Teknik Heuristik. Yogyakarta: Graha IImu.

Mahmudy, W. F. (2013). Algoritma Evolusi. Malang: Program Teknologi Informasi dan IImu Komputer, Universitas Brawijaya.

Prasetyo, Eko. (2012). Data Mining - Konsep dan Aplikasi Menggunakan MATLAB. Yogyakarta: Andi

Raharjo, Joko S. Dwi. (2013). Model Artificial Neural Network Berbasis Particle Swarm Optimization Untuk Prediksi Laju Inflasi, Jurnal Sistem Komputer, 3, pp. 10-21

Sari, Yuslena. (2017). Prediksi Harga Emas Menggunakan Metode Neural Network backpropagation Algoritma Conjugate Gradient. Jurnal Eltikom, Vol. 1, 2.

Sudjana. (1996). Metode Statistika. Bandung: PT. Tarsito

Yuliandar, D., Warsito, B., \& Yasin, H. (2012). Pelatihan Feed Forward Neural Network Menggunakan Algoritma Genetika dengan Metode Seleksi Turnamen untuk Data Time Series. Gaussian, Vol. 1, 65-72.

www.harga-emas.org 